\title{
Arterial Trip Length Characteristics
}
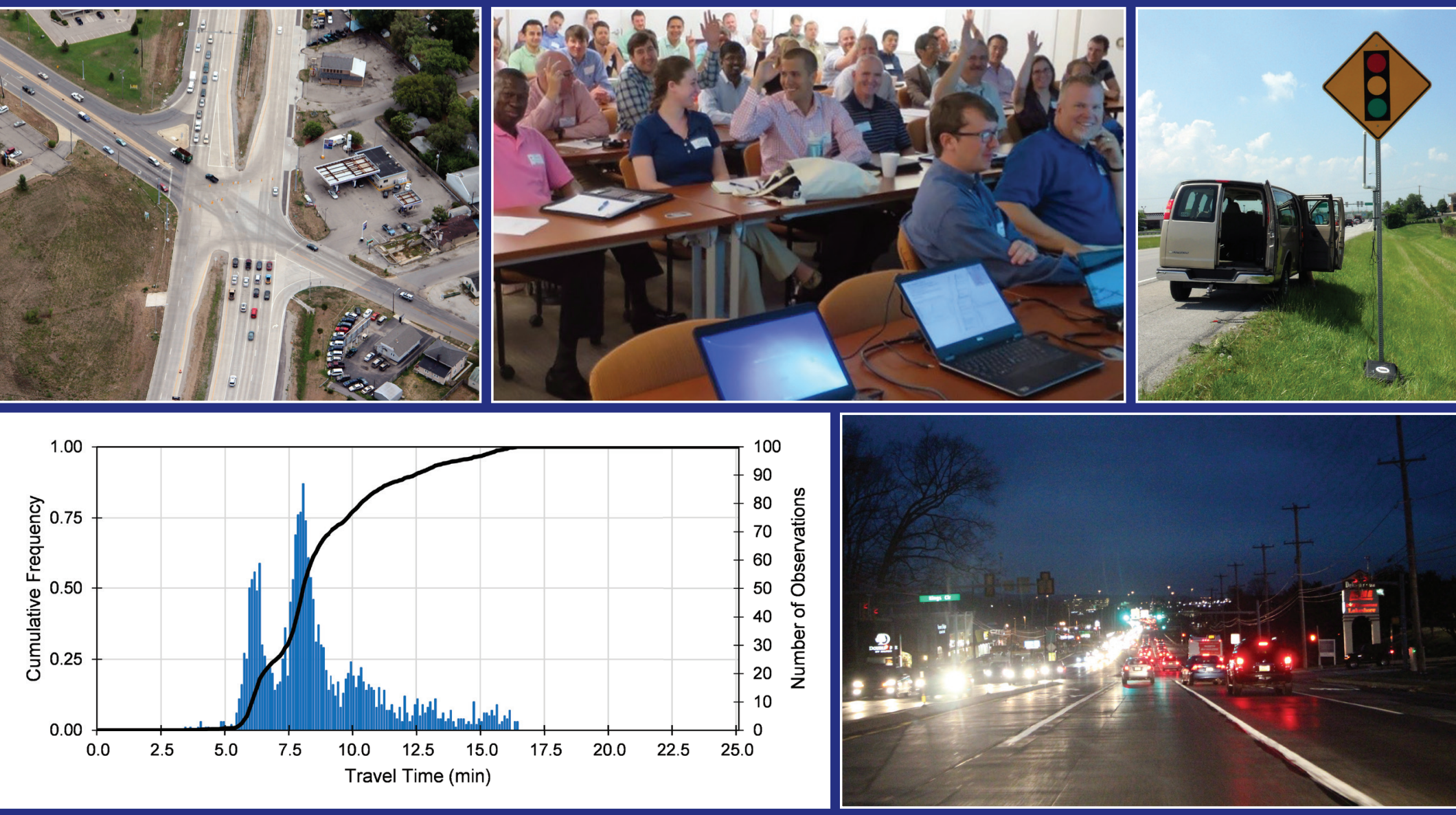

Stanley E. Young, Dennis So Ting Fong 


\title{
Arterial Trip Length Characteristics
}

\author{
Stanley E. Young \\ Traffax, Inc. \\ Dennis So Ting Fong \\ Traffax, Inc.
}

SBIR Phase 3 Transportation Research Project

Traffax, Inc.

September 2, 2016

\begin{tabular}{|l|l|}
\hline Deliverable Reference: & $\begin{array}{l}\text { D1.5 Arterial Trip Length Characteristics* } \\
\text { *Formerly titled Accessibility Measures Report }\end{array}$ \\
\hline Project Name: & $\begin{array}{l}\text { Sensor Fusion and MOE Development for Off-Line } \\
\text { Traffic Analysis of Real Time Data }\end{array}$ \\
\hline Contractor: & Traffax Inc \\
\hline Contract Number: & DTFH61-14-C-00035 \\
\hline Contract Term Start & $9 / 4 / 2014$ \\
\hline Contract Term End & $9 / 4 / 2017$ \\
\hline Key Personnel & Stan Young, Darcy Bullock, Dennis So Ting Fong \\
\hline
\end{tabular}




\section{Recommended Citation}

Young, S. E., and D. S. T. Fong. Arterial Trip Length Characteristics. Purdue University, West Lafayette, Indiana, 2017. https://doi.org/10.5703/1288284316560

\section{Acknowledgments}

This work was supported by Traffax/USDOT SBIR DTFH6114C00035. The contents of this paper reflect the views of the authors, who are responsible for the facts and the accuracy of the data presented herein, and do not necessarily reflect the official views or policies of the sponsoring organizations. These contents do not constitute a standard, specification, or regulation. 


\section{Table of Contents}

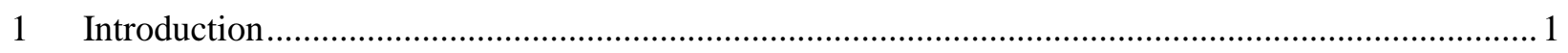

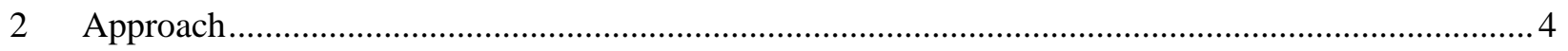

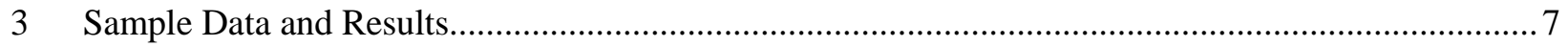

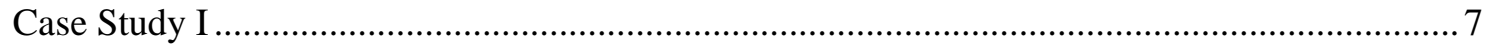

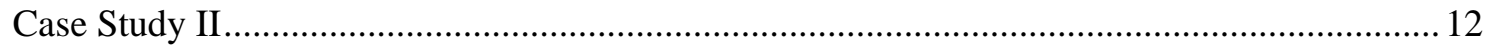

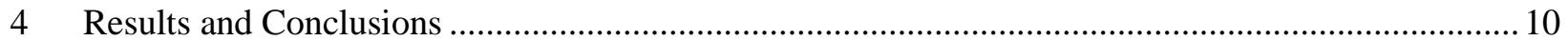

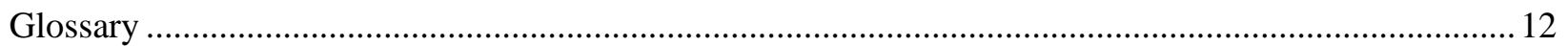

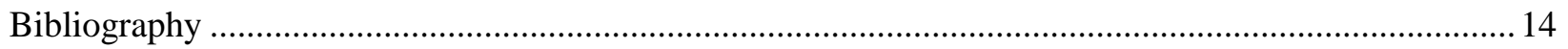




\section{Introduction}

Roadways provide both high-speed throughput as well as land access for goods and services. This dichotomy of purpose produces a spectrum of road types and classifications. At one end are high-speed limited access freeways designed specifically to connect cities and span large distances. At the other end of the spectrum are local roads and streets - low speed, with an inter-mix of vehicle traffic with pedestrians, cyclists and other activities; they are designed and regulated to safely maximize access to homes and buildings. The roadways in the middle, those that constantly balance throughput with land access, are generally referred to as arterials herein. Within the US, these roadways are typically

PROPORTION OF SERVICE

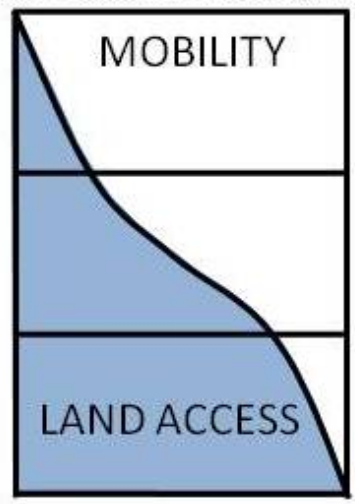

ARTERIALS

COLLECTORS

Figure 1 Throughput vs Land Access signal controlled at major intersections and have varying degrees of geometric design to allow for efficient turning movements while maintaining through traffic. This tradeoff between throughput and land access correlates with various attributes, such as posted speed limit, measured vehicle speed, density of signalized intersections, density of driveways, and density of un-signalized access points. Although these attributes correlate to the roadway use, none directly measure the extent the roadway is used for mobility versus land access. This report presents a method to directly assess the extent a roadway provides throughput versus land access by considering vehicle trip lengths collected using re-identification data.

Another graphical representation for throughput (also called mobility) versus land access is shown in Figure 2 from the Federal Highway Administration (FHWA) [1]. It conveys the same concept with a more granular roadway classification - from local streets to freeways. Note that there are no quantified scales on either the independent or dependent axis in either chart.

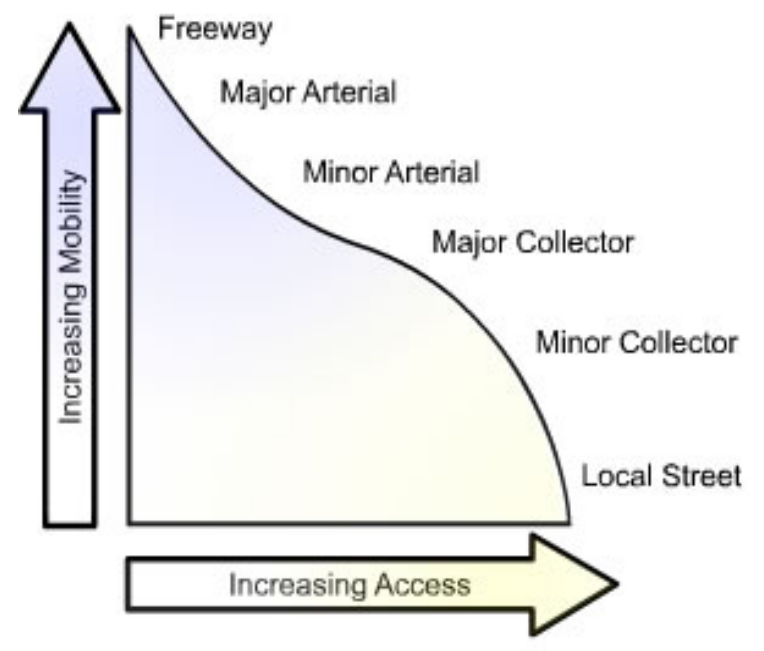

Figure 2 Principles of Access Management

Although subjective, the concept is embedded in roadway design. Roads intended for throughput have fewer intersections, fewer curb cuts for driveways and side streets, and posted speeds such that vehicles can efficiently traverse the corridor with minimal interruption. Similarly, roadways designed for access to shopping, goods, services, etc. have more frequent curb cuts, a greater number of intersections, and generally operate at a slower speed to maintain safety while providing increased opportunities for turning movements. Geometric and operational attributes of the facility (such as number of intersections, type of intersection control, number of curb cuts, speed, etc) can be measured and catalogued. These attributes provide an indirect measure of the roadway function where it falls on the throughput / land access spectrum. A collection of such measurable geometric attributes 
conveys the design objective of the roadway. This approach was used extensively in a recent study [4] conducted by the I-95 Corridor Coalition. Metrics, related to the number, type, and density of various roadway attributes, were correlated to the accuracy of traffic data as part of this study to assess the fidelity of outsourced probe data technology.

This research takes an alternative approach to quantifying the throughput versus land access properties of a roadway. Rather than using indirect attributes of the roadway design, such as intersection density or number of access points, this research attempts to directly measure how travelers use the roadway for trip making purposes. Specifically, in this approach, trip distance along a corridor is used as a quantifiable indicator of throughput versus land access continuum. A preponderance of long trips along a corridor would indicate the primary function of throughput. If the majority of trips along the corridor are short in duration, it would indicate that vehicles are accessing goods and services within the corridor. The distribution of trip length can be directly measured with modern traffic data re-identification technology. The share or proportion of short versus long trips reflects the level of conflicting demands on the corridor. This measurement can be made under various conditions such as time of day (rush hour versus non-rush hour), special events, or seasonal conditions.

The trip length statistic is an objective measure directly reflecting the subjective concept of throughput versus land access. As a directly measurable attribute, it is useful for engineering and performance assessment processes. It can supplant subjective judgment or indirect measures to provide a repeatable and defendable method for classifying roadways in order to compare and contrast roadway operations. Moreover, it can also be used to find like roadways across broad geographical spaces to compare for performance. Just as real-estate agents seek comparable houses in order to fairly benchmark home values, being able to objectively characterize roadway function use would allow engineers to fairly compare traffic, safety, signal, or energy performance on functionally similar roadways, regardless of their location.

Trip length characteristics have been applied to individuals or a demographic of individuals for transportation modeling or planning purposes for many years, however, until recently collecting this data at scale has been prohibitively expensive. Collected originally with travel surveys, such data can now be captured with GPS devices and, even more recently, with GPS enabled smartphone data that is crowd-sourced. Combined with trip purpose, trip length statistics can be developed for a number of trip types such as journey-towork, recreational, and

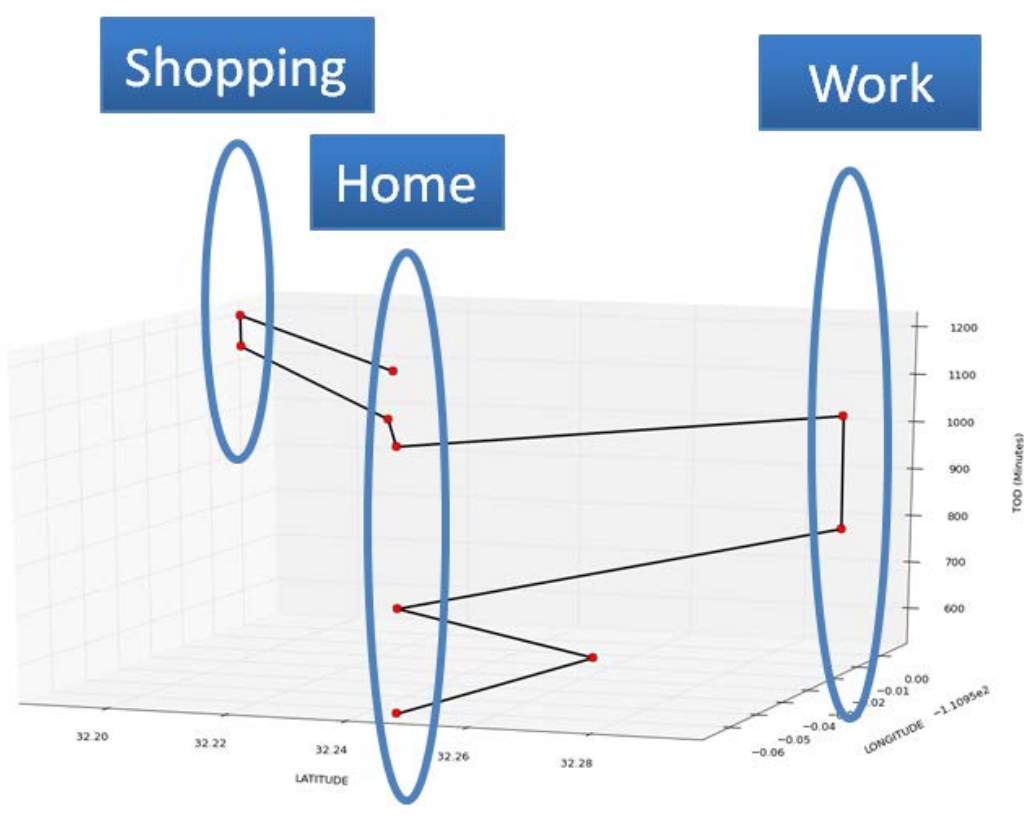

Figure 3 Time-Space Prism Diagram (Courtesy of Metropia, Inc) 
shopping. A time-space prism diagram, as shown in Figure 3, provides a visual of such data for a single compound trip for a day for an individual.

In a similar way, trip length statistics can be used to characterize roadway function. Rather than characterize the trip making relationships of an individual or demographic of people, trip length statistics for a roadway characterize how the corridor is utilized in terms of throughput and land access at various times of day. The distribution of trip lengths provides an indication of the proportion of vehicles using the roadway for throughput (longer trips) versus the number of vehicles using the roadway for access to services (shorter trips). Technology to collect such data cost effectively at scale has recently become availabe in re-identification data as will be explained in Section 2.0.

For clarification, a roadway vehicle trip (as opposed to a person vehicle trip) begins once the vehicle enters the facility, not from the drivers home location. Each roadway vehicle trip will begin at an access point such as an intersection (signalized or unsignalized), a ramp from an interchange, a sidestreet, or a driveway to a business or residence. Likewise, a roadway vehicle trip ends at a similar access point used to exit the facility, not at the final destination. To avoid confusion with the term trip length typically used in planning studies pertaining to individuals, the terms roadway vehicle trip and person vehicle trip are introduced and defined as follows:

- Roadway Vehicle Trip - the portion of a person vehicle trip that occurs on the roadway under study. A roadway vehicle trip begins once the vehicle enters the roadway and ends when it departs.

- Person Vehicle Trip - the path that a vehicle takes from the origin to the destination to accomplish a goal or purpose, such as going to work.

Note that a person vehicle trip will generate multiple roadway trips on different facilities and may even create multiple roadway vehicle trips on the same facility. For example, a person vehicle trip that accesses a coffee shop, and then contines on the same roadway to work will generate two roadway trips on the same facility: one roadway vehicle trip beginning at the point where the driver first accesses the facility and continuing to the entrance of the coffee shop, and another roadway vehicle trip from the access point leaving the coffee shop to the driver's final exit from the facility. Unless otherwise specificied in this document, the term trip will refer to a roadway vehicle trip. 


\section{Approach}

Measuring roadway trip lengths and the statistical distribution of those trip lengths on a specific facility, hereafter referred to as Roadway Trip Length Characteristic (RTLC), is the method proposed to objectively characterize roadway function on the scale of throughput versus land-access. The statistical distribution of roadway trip lengths on a specific facility will inform transportation engineers how the facility is utilized by the traveling public. The distribution of trip lengths can in turn be compared to the roadway design and prevailing signal timing plans to see if they are in harmony. Roadways with predominantly short trip lengths are anticipated to favor land access over throughput, and conversely those with predominantly long trip lengths are anticipated to favor throughput over land access. The amount and extent of variation of trip length on a facility provides an indication of the conflicting demand on the roadway.

Figure 4 illustrates this concept with a diagram of a corridor which has various numbered cross street intersections. Data on vehicle roadway trips has been aggregated to show the percentage of through vehicle trips versus the percentage of those which stop in the corridor, as well as intra-corridor trips.

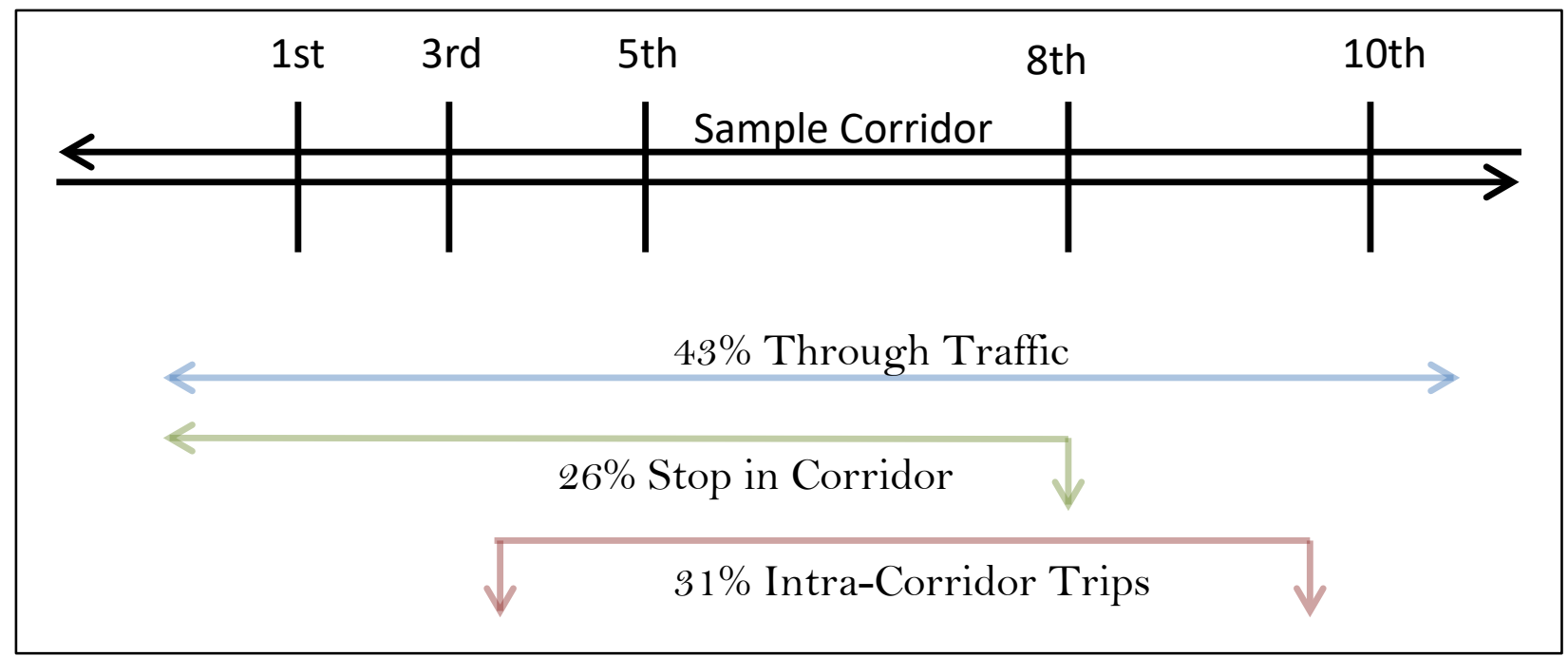

Figure 4 Concept of roadway vehicle trip characteristics within an arterial corridor

The ability to measure trip lengths at large scale has emerged within the last five years with reidentification technology. Re-identification technology can automatically identify a vehicle at various locations along a corridor. A vehicle identifier (ID) is recorded along with a time stamp at each location in a method analogous to recording license plate numbers, but with electronic identifiers used in wireless communications. The proliferation of consumer wireless technology allows re-identification to be performed automatically using unique identifiers in Bluetooth and Wi-Fi electronic communication protocols. Bluetooth or Wi-Fi based re-identification technology can be cost-effectively deployed along an arterial corridor to collect a large sample of roadway vehicle trips. Unlike license plate numbers, Bluetooth and Wi-Fi identifiers cannot be traced back to a user and therefore, this technology avoids issues with personally identifiable data. The trip length approach to roadway classification is illustrated using Bluetooth re-identification data sets. 
An illustration of the deployment of re-identification sensors is shown in Figure 5 based on the sample corridor from Figure 4. In Figure 5, letters A through G mark the placement of the sensors in the corridor. Sensors are deployed along the corridor at intersections $\left(1^{\text {st }}, 3^{\text {rd }}, 5^{\text {th }}, 8^{\text {th }}\right.$ and $10^{\text {th }}$ Streets $)$ and at the endpoints (referred to as external stations in planning level network origin and destination studies).

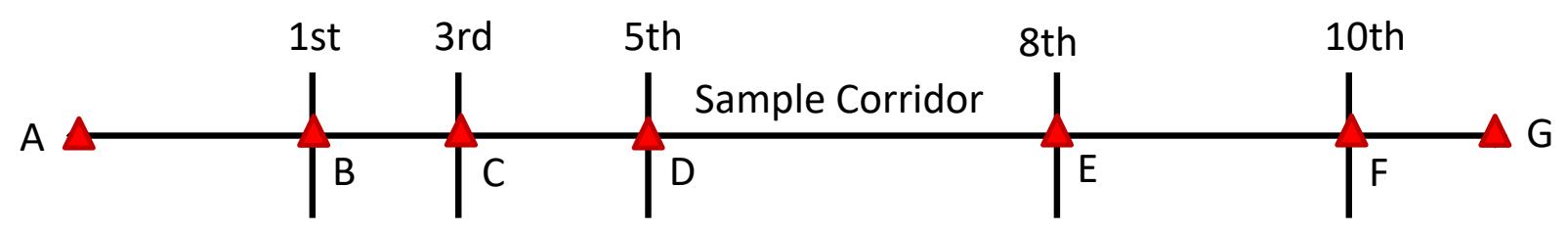

Figure 5 Placement of re-identification sensors for assessing corridor movement

Bluetooth and Wi-Fi re-identification sensors record the unique electronic identifiers of consumer electronics in vehicles as they pass, similar in principal to a license plate reader or electronic toll tag reader. A roadway vehicle trip is described by the series of sensors traversed. A vehicle that enters the roadway at $3^{\text {rd }}$ street and exits at $10^{\text {th }}$ street will be observed by sensors $\mathrm{C}, \mathrm{D}, \mathrm{E}$, and F, producing a sensor sequence pattern of CDEF. A roadway vehicle trip is designated by the sensor sequence pattern. A vehicle that traverses the entire corridor (left to right) would have a sequence pattern of ABCDEFG. The sequence pattern of sensors, such as ABCDEFG, is referred to as a trip chain. Knowing the distance between each sensor, trip lengths can be measured and various statistics about the trip length on the roadway can be calculated.

If the only access to the roadway is at the intersections where sensors are placed, the distance measured for each trip is highly accurate. However, if the roadway allows access to businesses between intersections, or if side street access between intersections is allowed, the distance measures are estimates accurate to the nearest intersection. For example, if a vehicle enters the study corridor at A, stops at a coffee shop along the route between $5^{\text {th }}$ street and $8^{\text {th }}$ street, and then continues the length of the corridor, two trip chains would be produced: ABCD and EFG. The location of the coffee shop relative to sensor D and $\mathrm{E}$ is not known and trip lengths reflect only distances to the nearest intersection. Distance A to D is used for accessing the coffee shop and distance $\mathrm{E}$ to $\mathrm{G}$ is used for leaving the coffee shop and continuing on the trip. The spatial granularity is limited by the placement density of sensors. A trip chain of BCD indicates that the vehicle was observed at three consecutive sensors. The vehicle may have entered the corridor at B ( $1^{\text {st }}$ street) or at any access point between A and B. Similarly, the vehicle may have exited at $\mathrm{D}\left(5^{\text {th }}\right.$ street $)$ or at any access point between sensors $\mathrm{D}$ and $\mathrm{E}$.

In the previous example of stopping at a coffee shop between $5^{\text {th }}$ and $8^{\text {th }}$ street and then continuing, the vehicle will be detected at all sensors A through G. However, there will a large time gap between the times at which sensors $\mathrm{D}$ and $\mathrm{E}$ register the vehicle. Processing of re-identification data typically involves a time threshold specification. If a vehicle identifier is not re-observed within a set amount of time anywhere in the corridor, the roadway vehicle trip is assumed to have ended. If the vehicle identifier is observed after the time threshold has expired, the system will identify this as the beginning of a new trip. This time threshold, referred to as a gap-out parameter, is typically 5 to 30 minutes depending on the application. A longer gap-out period, such as 30 minutes, may not register momentary stops, such as a fast-food drive-through, ATM, or gas station service. A shorter gap-out period, such as five minutes, will initiate a new roadway vehicle trip for any such activity in the corridor. 
In practice, there is a small probability that a re-identification sensor will not detect a vehicle even though a vehicle passes by the sensor. This has been estimated to be approximately 0.05 to 0.10 for Bluetooth based re-identification at highway speeds. This probability of missing a vehicle decreases at slower speeds. If a sensor fails to detect a vehicle, it may result in trip chains with missing letters such as ABDE or ABCE, when the vehicle actually traverses the trip chain ABCDE. In such cases it is assumed that the trips are contiguous such that $\mathrm{ABDE}$ or $\mathrm{ABCE}$ are mapped to the trip chain ABCDE. 


\section{$3 \quad$ Sample Data and Results}

\section{Case Study I}

The RTLC approach for characterizing trip length is illustrated using a re-identification data set collected as part of the I-95 Corridor Coalition's validation program for the Vehicle Probe Project (VPP). The VPP is an East Coast traffic monitoring system based on outsourced probe data. The University of Maryland, with funding from the I-95 Corridor Coalition, periodically collects re-identification data to provide ground-truth reference for validating the fidelity of travel time reported from outsourced vehicle probe data. The re-identification data is collected using Bluetooth technology.

Sensors were placed along MD-140 for a period of approximately two weeks, beginning on June 5, 2014 and extending to June 17, 2014. The corridor and the locations of the sensors are depicted in Figure 6. Along this corridor the number of lanes varies between 1 and 3 per direction with average signal density of 1.8 signals per mile. Average Annual Daily Traffic (AADT) along the corridor averages 31,440 and the posted speed limit varies between 30 and $55 \mathrm{MPH}$.

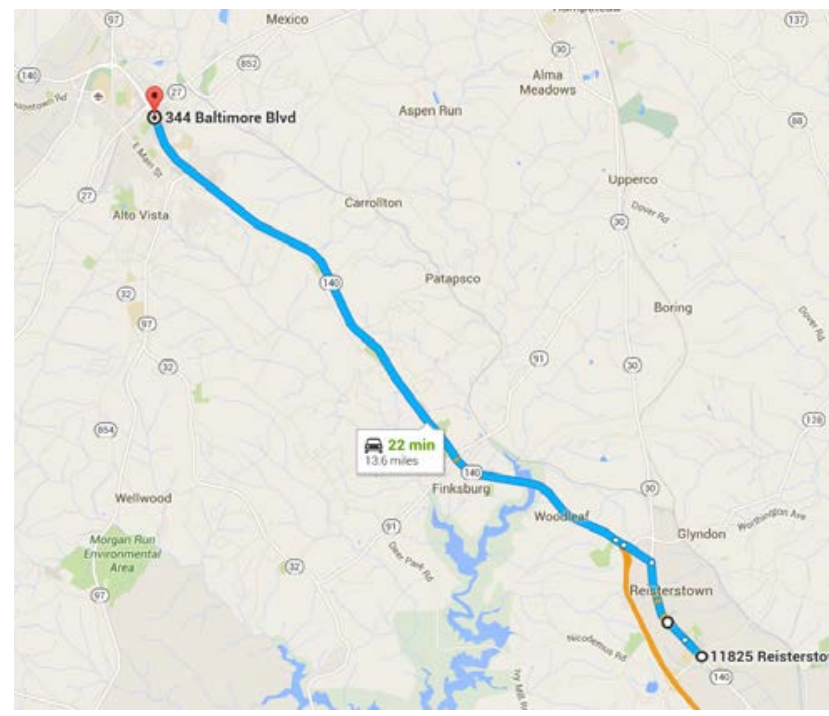

Figure 6 A - Location of study corridor

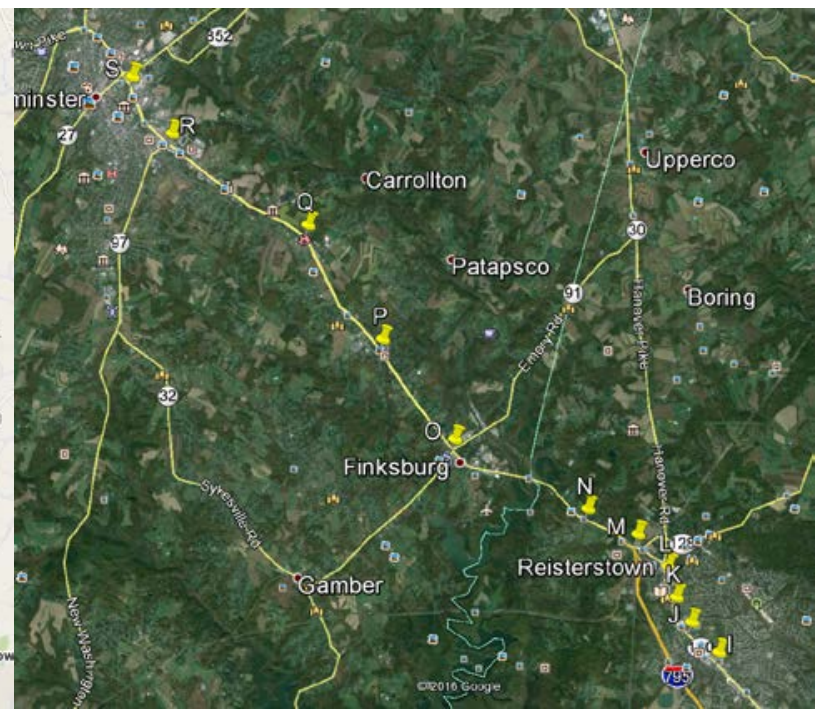

B - Placement of re-identification sensors

Sensors are labeled I through S beginning at the southern end of the corridor where MD-140 intersects Cherry Hill Road East / Franklin Boulevard. The study corridor ends at the intersection of Manchester Road to the north end. The cross street sensor placement locations and approximate distances from the southernmost sensor, I, are shown in Table 1.

Trip sequences were assessed for all Bluetooth re-identified vehicles in the corridor during the data collection period. Bluetooth is able to sample approximately $5 \%$ of all trips.

Table 1 Sensor Locations

\begin{tabular}{|c|l|c|}
\hline Sensor & \multicolumn{1}{|c|}{ Cross Street } & Milepost \\
\hline I & Cherry Hill Rd / Franklin Blvd & 0 \\
\hline J & Walgrove Rd & 0.6 \\
\hline K & Glydon Dr & 1.1 \\
\hline L & Chatsworth Ave & 1.6 \\
\hline M & Butler Rd / Begin Westminster Pike & 2.4 \\
\hline N & Gores Mill Rd & 3.3 \\
\hline O & Gamber Rd / Emory Rd & 5.7 \\
\hline P & Suffolk Rd & 7.6 \\
\hline Q & Reese Rd & 9.8 \\
\hline R & Washington Rd / Malcolm Rd & 12.3 \\
\hline S & Manchester Rd & 13.5 \\
\hline
\end{tabular}


Table 2 Trip Chains

\begin{tabular}{|c|c|c|}
\hline Trip Chain & $\begin{array}{c}\text { Vehicle Trip } \\
\text { Count }\end{array}$ & $\begin{array}{c}\text { Mean Trip Time } \\
\text { (minutes) }\end{array}$ \\
\hline SR & 4511 & 3.44 \\
RS & 4273 & 4.01 \\
SRQPONM & 2673 & 16.43 \\
MNOPQRS & 2431 & 17.77 \\
IJ & 1511 & 2.31 \\
JI & 1457 & 2.39 \\
MNO & 1208 & 5.22 \\
ONM & 1134 & 5.11 \\
MNOPQR & 968 & 15.01 \\
SRQPON & 920 & 15.73 \\
ON & 911 & 4.04 \\
LKJI & 874 & 5.91 \\
IJKL & 860 & 5.84 \\
NO & 839 & 4.00 \\
NOP & 800 & 6.48 \\
RQPONM & 772 & 14.04 \\
QPON & 733 & 9.30 \\
PON & 714 & 6.54 \\
OP & 696 & 3.93 \\
NOPQRS & 675 & 16.84 \\
\hline
\end{tabular}

Trip chains were created based on the collected data. The 20 most frequently observed trip chains are shown in Table 2 along with the number of observations. This table has been truncated due to its size. The number of unique trip chains observed with 20 or more trips during this period exceeded 200.

As observed in Table 2, the base trip chain data is often reciprocal. This means that the number of trips, for trip chains between two locations but in the opposite direction, is often nearly equal when assessed over a long period of time. For example, the two most common trip chains observed in the study corridor were SR and RS, with observed number of trips totaling 4511 and 4273 respectively. Most of the entries in the top 20 trip chains appear in reciprocal pairs. This is expected when assessing trips over a multi-day period. Most person vehicle trips are symmetrical, meaning that the vehicle eventually returns to the trip origin along the same path, but in the opposite direction, creating reciprocal roadway vehicle trips in the process. If a trip chain table which spans multiple days does not contain reciprocal pairs as illustrated in Table 2, it is a sign of unusual trip making patterns for the corridor, or a data collection problem. If the analysis period is only for a portion of the day, such as morning or afternoon peak period, the reciprocal nature of the trip chains may diminish substantially.

Re-identification data can be used to construct matrices showing where the vehicle was first observed and last observed. Often referred to as origin-destination matrixes, or O-D matrices, such tables provide a detailed view of the demand between various parts of the corridor. Note that the entries in the O-D table indicate 'last seen', not necessarily where the vehicle entered or exited as previously discussed. However, since most roadway access is at major intersections, the O-D matrix is highly correlated to the intersection O-D. For example, a trip that started at sensor L, Chatsworth Avenue, and ended at sensor Q, Reese Road, infers that the vehicle entered the corridor somewhere after Glydon Drive (sensor K) up to and including Chatsworth Avenue (sensor L). Similarly, the vehicle exited at or after sensor Q and before sensor R. In total, over 46,000 roadway vehicle trips were observed and classified in the OD matrix as shown in Table 3.

Note that the O-D matrix only contains trip chains with 50 or more observed trip counts. As a result, any O-D pair with less than 50 observed trips over the approximately two week period will result in a ' 0 ' entry in the O-D matrix. This accounts for the 0 entries between sensors I through $\mathrm{L}$ to and from sensors $\mathrm{M}$ through S. If the trip chain data were exhaustively processed (including trip chains with counts less than 50), some of these entries may be greater than 0 , but all are less than 50 . The pattern in the table 
corresponds to the location of a major intersection of MD-140 with Interstate 795. I-795 is a spur that terminates at MD-140 at sensor M. Through traffic on MD-140 north of the intersection with I-795 would merge/diverge with I-795 at $\mathrm{M}$ for trips to/from the Baltimore metropolitan region. A similar relationship holds for vehicle traffic south of the intersection of I-795 and sensor L.

Another representation of the data is shown in Table 4. This table provides counts at each station for trips that began at that sensor (origin) or ended at that station (destination). The table also provides the number of trips which included that sensor, but were neither the origin nor destination. This is the row labeled 'Through'. The end points of the corridor, sensors I and S, by definition will contain no through trips, as they represent the extents of the study area. Sensors M and L also contain no through trips owing to the phenomenon resulting from the intersection of I-795 previously discussed. If trip chains less than 50 were processed, the through trips of $\mathrm{M}$ and $\mathrm{L}$ would likely be greater than zero, but still small in comparison to other sensors in the study corridor.

Table 3 Origin-Destination Matrix of Trips

\begin{tabular}{|c|c|c|c|c|c|c|c|c|c|c|c|c|}
\hline \multirow{2}{*}{\multicolumn{2}{|c|}{ OD Trips }} & \multicolumn{11}{|c|}{ Destination } \\
\hline & & 1 & $\mathrm{~J}$ & $\mathrm{~K}$ & $L$ & $M$ & $\mathbf{N}$ & 0 & $\mathbf{P}$ & $\mathbf{Q}$ & $\mathbf{R}$ & $S$ \\
\hline \multirow{11}{*}{ 高 } & $\mathrm{I}$ & 0 & 1635 & 601 & 1003 & 0 & 0 & 0 & 0 & 0 & 0 & 0 \\
\hline & $J$ & 1614 & 0 & 200 & 325 & 0 & 0 & 0 & 0 & 0 & 0 & 0 \\
\hline & K & 697 & 167 & 0 & 537 & 0 & 0 & 0 & 0 & 0 & 0 & 0 \\
\hline & L & 1030 & 255 & 563 & 0 & 166 & 0 & 0 & 0 & 0 & 0 & 0 \\
\hline & $M$ & 0 & 0 & 0 & 112 & 0 & 702 & 1261 & 610 & 446 & 1137 & 2804 \\
\hline & $\mathrm{N}$ & 0 & 0 & 0 & 0 & 571 & 0 & 839 & 876 & 382 & 847 & 839 \\
\hline & 0 & 0 & 0 & 0 & 0 & 1134 & 911 & 0 & 696 & 264 & 318 & 398 \\
\hline & $\mathbf{P}$ & 0 & 0 & 0 & 0 & 580 & 807 & 632 & 0 & 165 & 166 & 156 \\
\hline & $\mathbf{Q}$ & 0 & 0 & 0 & 0 & 524 & 810 & 324 & 246 & 0 & 416 & 416 \\
\hline & $\mathbf{R}$ & 0 & 0 & 0 & 0 & 772 & 712 & 250 & 200 & 394 & 0 & 4798 \\
\hline & $S$ & 0 & 0 & 0 & 0 & 2814 & 1251 & 502 & 251 & 457 & 4938 & 0 \\
\hline
\end{tabular}

Table 4 Origin-Destination ‘Through Trip’ Summary

\begin{tabular}{|c|c|c|c|c|c|c|c|c|c|c|c|}
\hline & \multicolumn{10}{|c|}{ Sensors } \\
\cline { 2 - 13 } & $\mathbf{I}$ & $\mathbf{J}$ & $\mathbf{K}$ & $\mathbf{L}$ & $\mathbf{M}$ & $\mathbf{N}$ & $\mathbf{O}$ & $\mathbf{P}$ & $\mathbf{Q}$ & $\mathbf{R}$ & S \\
\hline Origin & 3239 & 2139 & 1401 & 2014 & 7072 & 4354 & 3721 & 2506 & 2736 & 7126 & 10213 \\
\hline Destination & 3341 & 2057 & 1364 & 1977 & 6561 & 5193 & 3808 & 2879 & 2108 & 7822 & 9411 \\
\hline Through & 0 & 3195 & 2443 & 0 & 0 & 12029 & 15965 & 14688 & 12919 & 9670 & 0 \\
\hline
\end{tabular}

Combining the trip chain information (as shown in Table 2) with the distance between sensors (as shown in Table 1) provides the base data to illustrate the distribution of roadway vehicle trip lengths. A histogram of observed roadway vehicle trip lengths is illustrated in Figure 7. Note that the histogram indicates two peaks, one at 1-2 miles, and the other at 9-11 miles.

The peak at 9-11 miles corresponds to trip distances that span the northern portion of the corridor between sensors $\mathrm{M}$ and $\mathrm{S}$, indicating a large number of vehicles traverse the entire northern portion of the corridor to access I-795, accounting for $21 \%$ of all trips. Note that due to the location of sensor $\mathrm{M}$ with respect to merge/diverge ramps of I-795, trips that begin or end at either sensor $\mathrm{M}$ or $\mathrm{N}$ indicate a trip that accessed I-795. 
The peak, at 1-2 miles, reflects that a large number of vehicles access MD-140 for only a short distance and then exit the corridor to either another road or to services along the road. If combined with the $0-1$ mile trips, the trips from 0 to 2 miles account for $47 \%$ of roadway vehicle trips in the corridor.

The average trip length for the corridor was 4.2 miles. However, as evidenced by the significant bimodal distribution, the average trip length does not reflect the dichotomy of trip purpose (short versus long) that exists in the corridor.

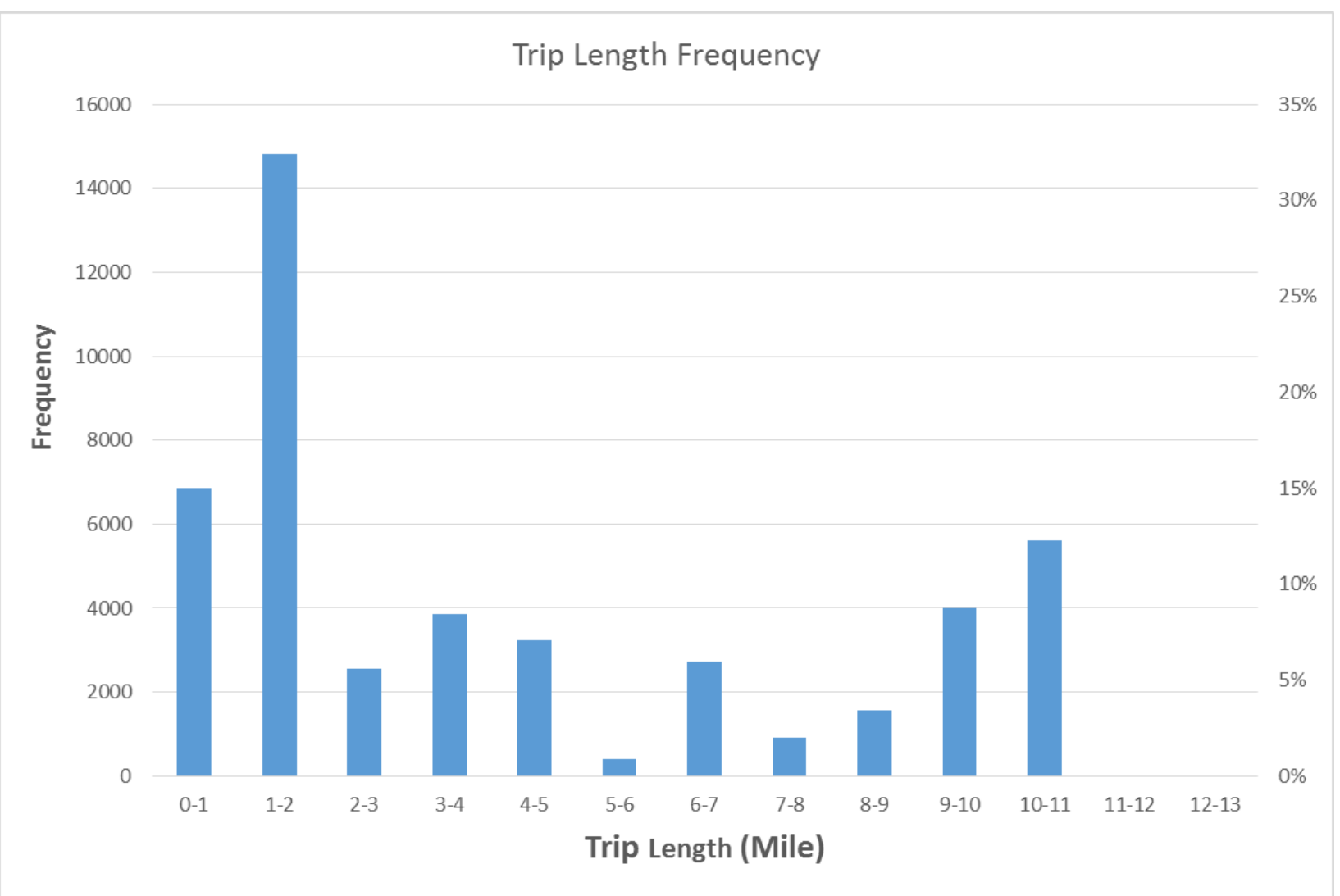

Figure 7 Histogram of observed trip length frequency

A cumulative frequency diagram (CFD) of trip length data is illustrated in Figure 8. The cumulative distribution view of the data may not be as intuitive as the histogram approach, but allows for multiple distributions to be viewed simultaneously.

For example, the above analysis can be further refined by time of day. Using the hours from 6AM to 9AM and 3:30 PM to 6:30 PM as peak hours for journey-to-work trips, the analysis is separated into peak hour and off-peak hour. The corresponding results for the trips distribution for Peak versus Non-Peak are graphed in Figure 8 along with the CFD for All-Day results. The resulting CFD chart shows that trip length distribution does not vary significantly by time of day. 


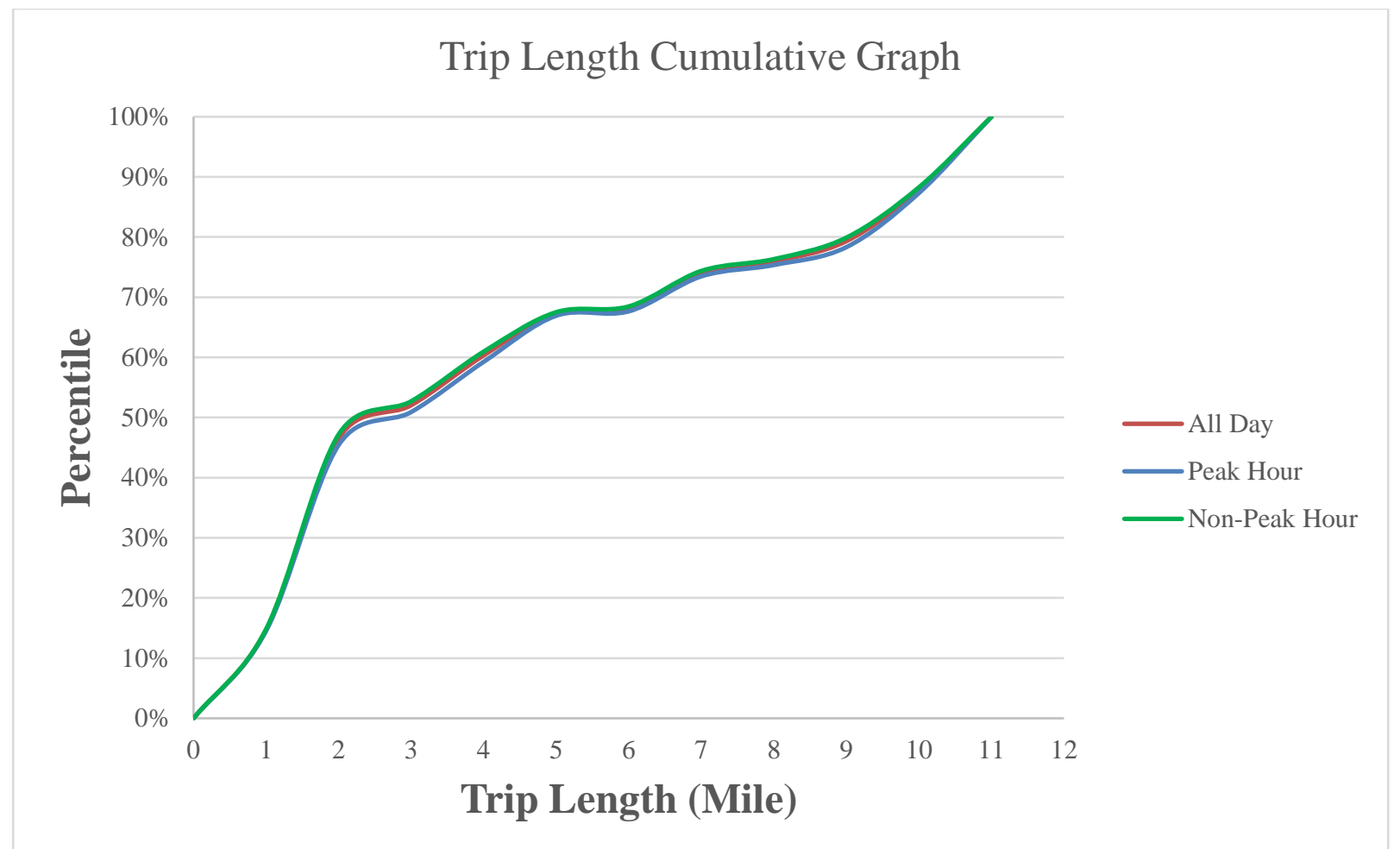

\section{Figure 8 Cumulative frequency diagram of trip length in the sample corridor}

A top level summary chart is shown below in Figure 9 for trips lengths in Case Study I. It presents the information from trip length distribution analysis in a simplified graphic showing how travelers use the corridor. Similar to the histogram, it shows the conflicting demand on the corridor between short trips (less than 2 miles) and long trips (greater than 8 miles).

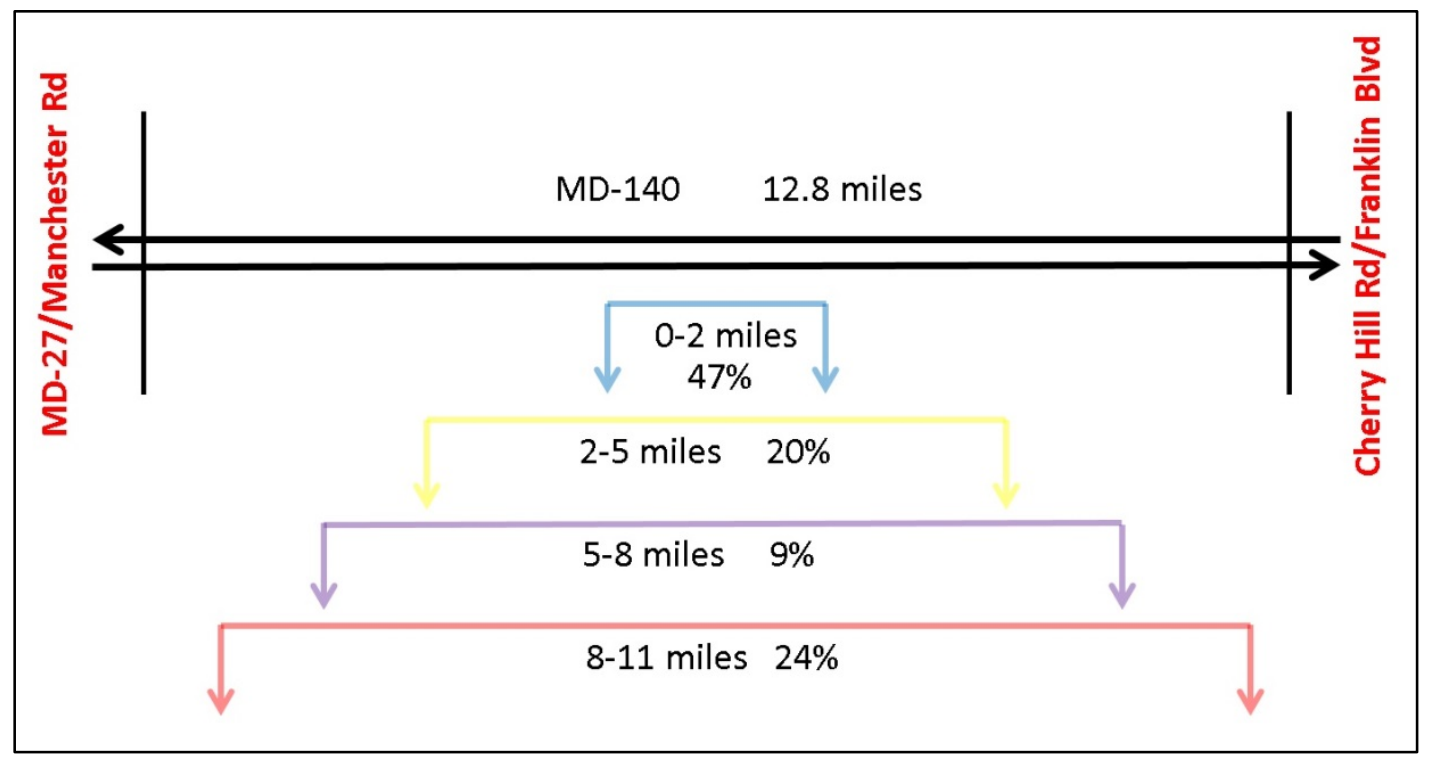

Figure 9 Use of corridor graphic 


\section{Case Study II}

The RTLC approach for characterizing trip length is applied to a second case study, again using a reidentification data set collected as part of the I-95 Corridor Coalition's validation program for the Vehicle Probe Project (VPP). The second case study comes from Route 37 in New Jersey connecting Lakehurst to Seaside Heights. Along this corridor the number of lanes varies between 2 and 3 per direction with average signal density of one signal per mile. Average Annual Daily Traffic (AADT) along the corridor averages 37,550 and the posted speed limit is $50 \mathrm{MPH}$.

Bluetooth re-identification sensors were deployed from NJ-35 near the coast at Seaside Height to Colonial Dr. in Lakehurst from June 30 to July 12, 2015. The corridor and the locations of the sensors are depicted in Figure 10. Sensors are labels A,R,C,D,E,F,G,H,I,J,K,L,M,N,O,P,Q,B,S from east to west along the corridor (sensors $\mathrm{B}$ and $\mathrm{R}$ were accidentally swapped in the field).

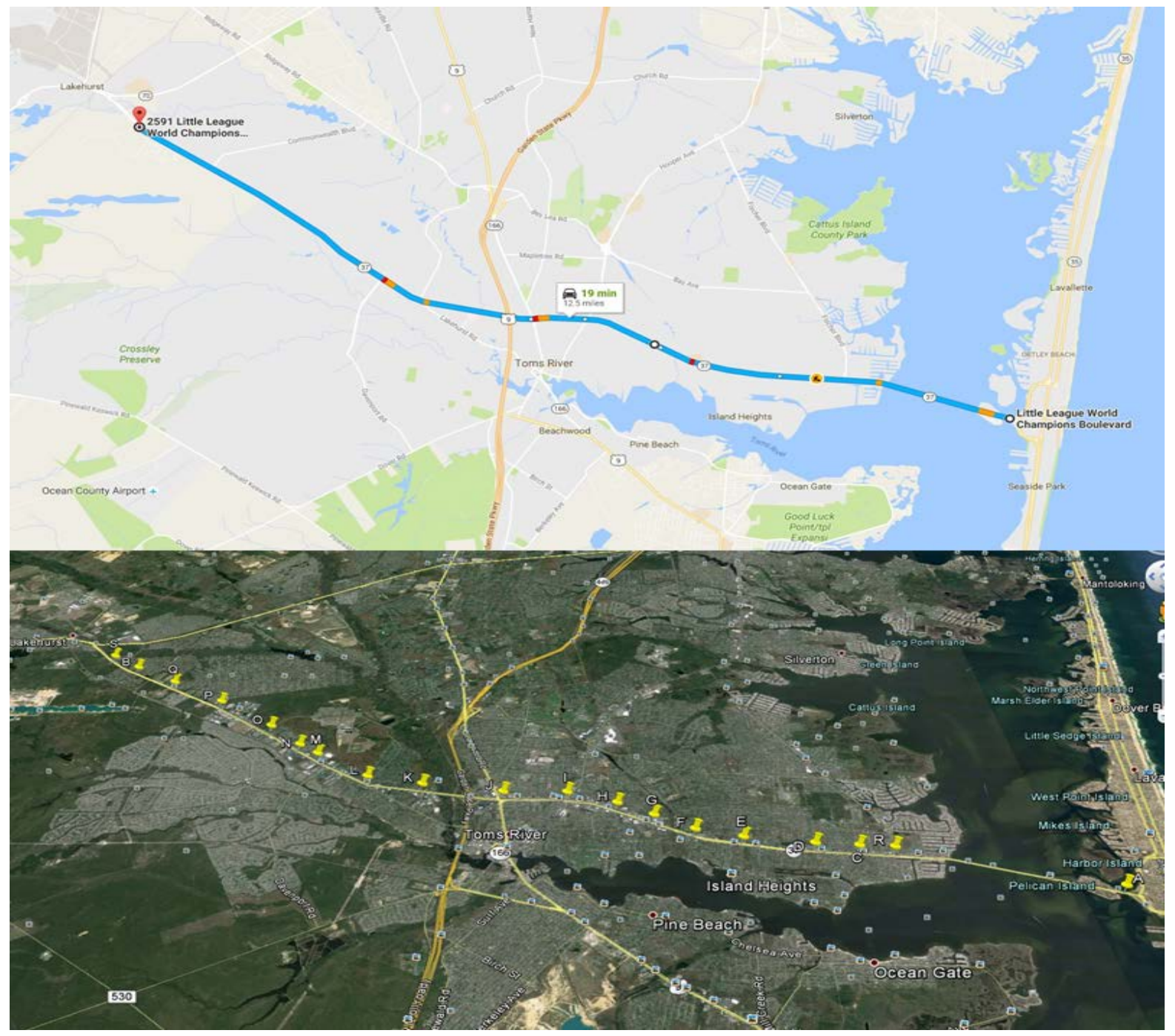

Figure 10 Upper: Location of case study along route NJ-37. Bottom: Placement of sensors 
Distances between sensors are provided in Table 5. In total, over 46000 roadway vehicle trips were observed and classified in the OD matrix as shown in Table 6. Note that the O-D matrix only contains trip chains with 50 or more observed trip counts. The matrix pattern reveals few trips that span sensors $\mathrm{J}$ and $\mathrm{K}$ as noted by mainly zero entries in the upper right and lower left quadrants.

Table 5 provides counts at each station for trips that began at that sensor (origin) or ended at that sensor (destination). The table also provides the number of trips which included that sensor, but were neither the origin nor destination in the 'Through' row.

Table 5 Sensor Locations for Case Study II

\begin{tabular}{|c|c|}
\multicolumn{1}{c}{ Sensor } & Distance \\
\hline A & 0 \\
\hline R & 2.23 \\
\hline C & 2.59 \\
\hline D & 3.04 \\
\hline E & 3.76 \\
\hline F & 4.27 \\
\hline G & 4.75 \\
\hline H & 5.18 \\
\hline I & 5.74 \\
\hline J & 6.44 \\
\hline K & 7.34 \\
\hline L & 7.98 \\
\hline M & 8.75 \\
\hline N & 9.05 \\
\hline O & 9.60 \\
\hline P & 10.50 \\
\hline Q & 11.32 \\
\hline B & 11.98 \\
\hline S & 12.47 \\
\hline
\end{tabular}


Table 6 Origin-Destination Matrix of Trips for Case Study II

\begin{tabular}{|c|c|c|c|c|c|c|c|c|c|c|c|c|c|c|c|c|c|c|c|c|c|}
\hline \multirow{2}{*}{\multicolumn{2}{|c|}{$\begin{array}{c}\text { OD } \\
\text { Trips }\end{array}$}} & \multicolumn{20}{|c|}{ Destination } \\
\hline & & $\mathbf{A}$ & $\mathbf{R}$ & $\mathrm{C}$ & D & $\bar{E}$ & $\mathbf{F}$ & G & $\mathbf{H}$ & I & $\mathbf{J}$ & $\mathbf{K}$ & $\mathbf{L}$ & $\mathbf{M}$ & $\mathbf{N}$ & $\mathbf{O}$ & $\mathbf{P}$ & $\mathbf{Q}$ & B & $S$ & Total \\
\hline \multirow{19}{*}{ 葛 } & $\mathbf{A}$ & 0 & 195 & 0 & 0 & 0 & 0 & 0 & 0 & 0 & 156 & 0 & 0 & 0 & 0 & 0 & 0 & 0 & 0 & 0 & 351 \\
\hline & $\mathbf{R}$ & 173 & 0 & 380 & 297 & 459 & 608 & 77 & 661 & 579 & 1915 & 70 & 81 & 0 & 0 & 0 & 0 & 0 & 0 & 115 & 5415 \\
\hline & C & 0 & 222 & 0 & 100 & 51 & 77 & 0 & 0 & 66 & 165 & 0 & 0 & 0 & 0 & 0 & 0 & 0 & 0 & 0 & 681 \\
\hline & D & 0 & 388 & 109 & 0 & 156 & 141 & 52 & 159 & 108 & 178 & 0 & 0 & 0 & 0 & 0 & 0 & 0 & 0 & 0 & 1291 \\
\hline & $\mathbf{E}$ & 0 & 437 & 52 & 127 & 0 & 306 & 70 & 479 & 172 & 339 & 51 & 0 & 0 & 0 & 0 & 0 & 0 & 0 & 0 & 2033 \\
\hline & $\mathbf{F}$ & 0 & 631 & 64 & 135 & 231 & 0 & 80 & 110 & 203 & 268 & 0 & 0 & 0 & 0 & 0 & 0 & 0 & 0 & 0 & 1722 \\
\hline & G & 0 & 109 & 0 & 0 & 103 & 123 & 0 & 145 & 161 & 210 & 0 & 0 & 0 & 0 & 0 & 0 & 0 & 0 & 0 & 851 \\
\hline & $\mathbf{H}$ & 0 & 648 & 0 & 71 & 445 & 107 & 114 & 0 & 271 & 320 & 0 & 0 & 0 & 0 & 0 & 0 & 0 & 0 & 0 & 1976 \\
\hline & $\mathbf{I}$ & 0 & 548 & 0 & 68 & 136 & 156 & 104 & 326 & 0 & 1349 & 255 & 105 & 0 & 0 & 0 & 0 & 0 & 0 & 50 & 3097 \\
\hline & $\mathbf{J}$ & 79 & 1457 & 96 & 100 & 231 & 169 & 106 & 300 & 958 & 0 & 208 & 137 & 0 & 0 & 0 & 0 & 0 & 0 & 0 & 3841 \\
\hline & $\mathbf{K}$ & 0 & 0 & 0 & 0 & 0 & 0 & 0 & 0 & 132 & 130 & 0 & 629 & 311 & 408 & 111 & 233 & 0 & 0 & 338 & 2292 \\
\hline & $\mathbf{L}$ & 0 & 0 & 0 & 0 & 0 & 0 & 0 & 0 & 67 & 142 & 434 & 0 & 114 & 96 & 79 & 54 & 0 & 0 & 76 & 1062 \\
\hline & $\mathbf{M}$ & 0 & 0 & 0 & 0 & 0 & 0 & 0 & 0 & 0 & 58 & 283 & 220 & 0 & 542 & 99 & 291 & 0 & 172 & 387 & 2052 \\
\hline & $\mathbf{N}$ & 0 & 0 & 0 & 0 & 0 & 0 & 0 & 0 & 0 & 0 & 382 & 120 & 542 & 0 & 0 & 0 & 0 & 0 & 65 & 1109 \\
\hline & $\mathbf{O}$ & 0 & 0 & 0 & 0 & 0 & 0 & 0 & 0 & 0 & 0 & 102 & 105 & 76 & 0 & 0 & 55 & 0 & 0 & 53 & 391 \\
\hline & $\mathbf{P}$ & 0 & 0 & 0 & 0 & 0 & 0 & 0 & 0 & 0 & 0 & 127 & 66 & 213 & 0 & 61 & 0 & 87 & 206 & 604 & 1364 \\
\hline & $\mathbf{Q}$ & 0 & 0 & 0 & 0 & 0 & 0 & 0 & 0 & 0 & 0 & 0 & 0 & 0 & 0 & 0 & 112 & 0 & 440 & 465 & 1017 \\
\hline & B & 0 & 0 & 0 & 0 & 0 & 0 & 0 & 0 & 0 & 0 & 0 & 0 & 0 & 0 & 0 & 72 & 281 & 0 & 260 & 613 \\
\hline & $\mathrm{S}$ & 0 & 99 & 0 & 0 & 0 & 0 & 0 & 0 & 0 & 0 & 174 & 121 & 383 & 53 & 72 & 641 & 588 & 161 & 0 & 2292 \\
\hline \multicolumn{2}{|c|}{ Total } & 252 & 4734 & 701 & 898 & 1812 & 1687 & 603 & 2180 & 2717 & 5230 & 2086 & 1584 & 1639 & 1099 & 422 & 1458 & 956 & 979 & 2413 & 33450 \\
\hline
\end{tabular}

Table 7 Origin-Destination-Through Trip Summary for Case Study II

\begin{tabular}{|c|c|c|c|c|c|c|c|c|c|c|c|c|c|c|c|c|c|c|c|}
\hline & \multicolumn{19}{|c|}{ Destination } \\
\hline & $\mathbf{A}$ & $\mathbf{R}$ & $\mathbf{C}$ & D & $\mathbf{E}$ & $\mathbf{F}$ & G & $\mathbf{H}$ & I & $\mathbf{J}$ & $\mathbf{K}$ & $\mathbf{L}$ & $\mathbf{M}$ & $\mathbf{N}$ & $\mathbf{O}$ & $\mathbf{P}$ & $\mathbf{Q}$ & B & $\mathbf{S}$ \\
\hline Origin & 351 & 5415 & 681 & 1291 & 2033 & 1722 & 851 & 1976 & 3097 & 3841 & 2292 & 1062 & 2052 & 1109 & 391 & 1364 & 1017 & 613 & 2292 \\
\hline Dest. & 252 & 4734 & 701 & 898 & 1812 & 1687 & 603 & 2180 & 2717 & 5230 & 2086 & 1584 & 1639 & 1099 & 422 & 1458 & 956 & 979 & 2413 \\
\hline Thru & 0 & 235 & 7104 & 8657 & 9111 & 8274 & 8784 & 8186 & 6505 & 953 & 854 & 1305 & 2856 & 3536 & 1481 & 2158 & 3681 & 3927 & 0 \\
\hline
\end{tabular}


Combining the trip chain information (as shown in Table 6) with the distance between sensors (as shown in Table 5) provides the base data for the calculation of roadway vehicle trip lengths. A histogram of observed roadway vehicle trip lengths is illustrated in Figure 11. Note that the histogram has primarily a single peak at 0-2 miles, with gradually decreasing trip frequency as trip distances increase to 6 miles. A few vehicles travel the length of the corridor, indicated by the small number of trips at 11 miles.

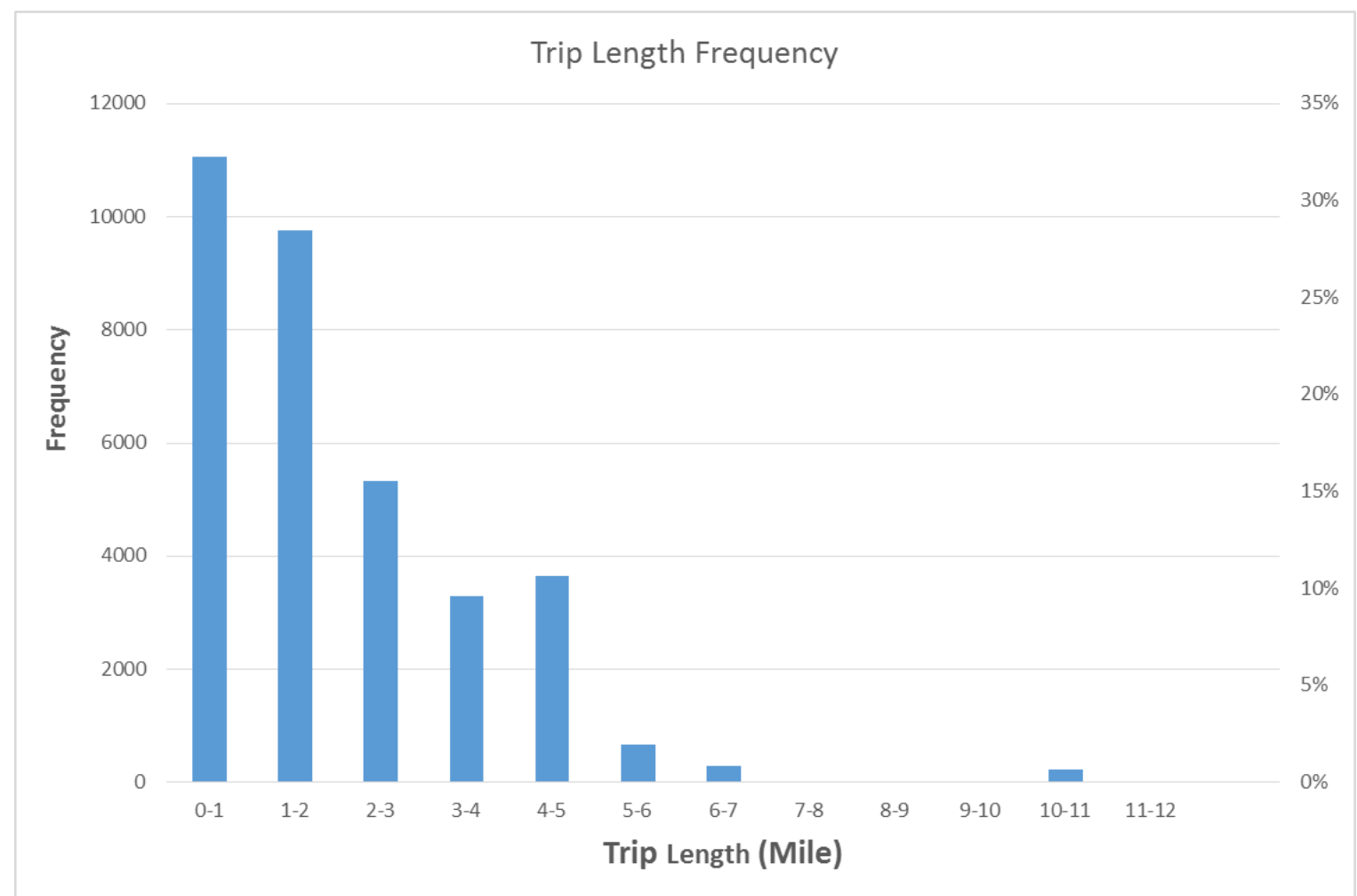

Figure 11 Histogram of observed trip length frequency 
A cumulative frequency diagram of trip length data is illustrated in Figure 12. In addition to the overall trip length distribution, the peak hour and off-peak are also plotted revealing little difference in trip characteristics for peak versus non-peak similar to Case Study I.

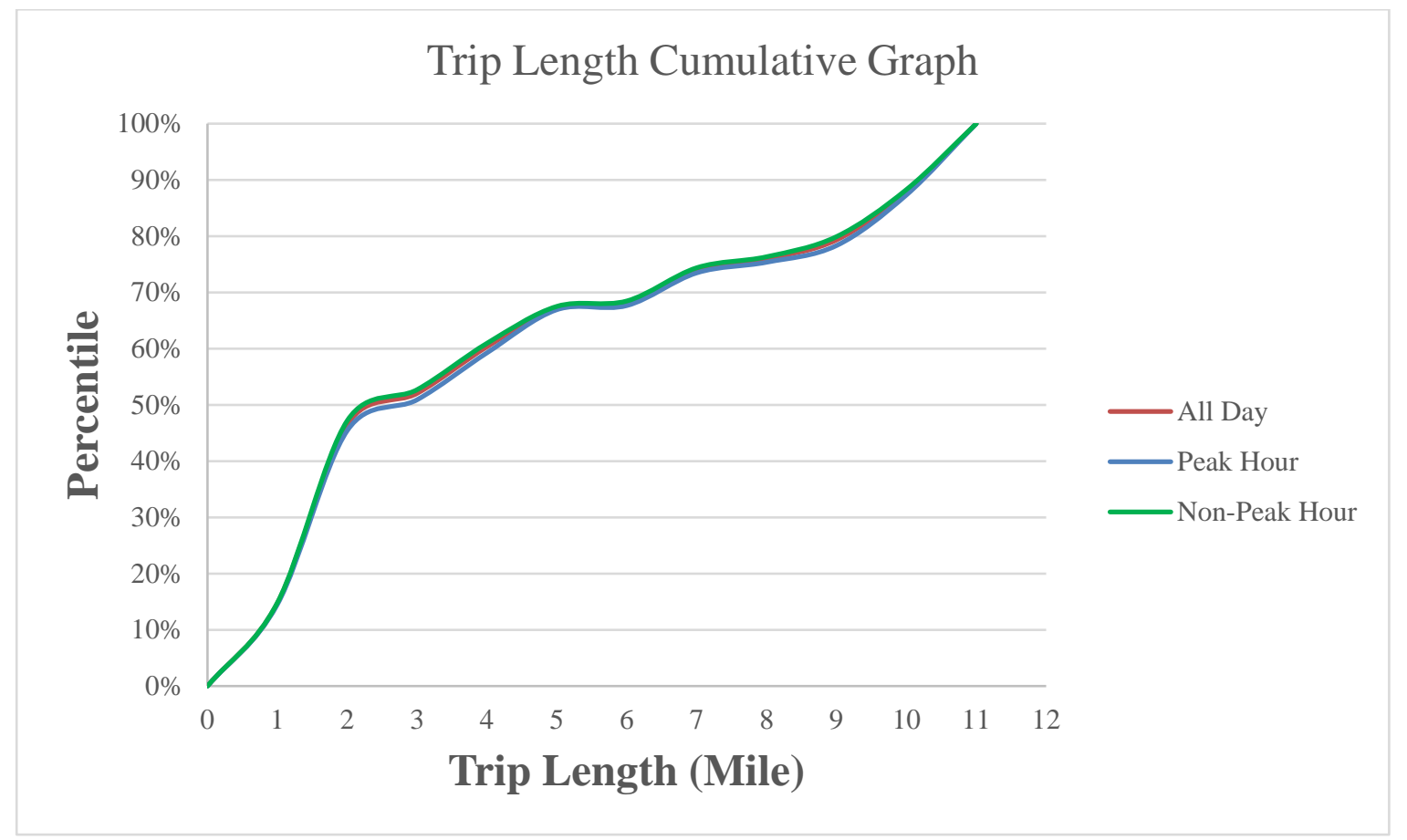

Figure 12 Cumulative frequency diagram of trip length in the sample corridor

A top level summary chart in Figure 13 presents the information from trip length distribution analysis into a simplified graphic showing how travelers use the corridor.

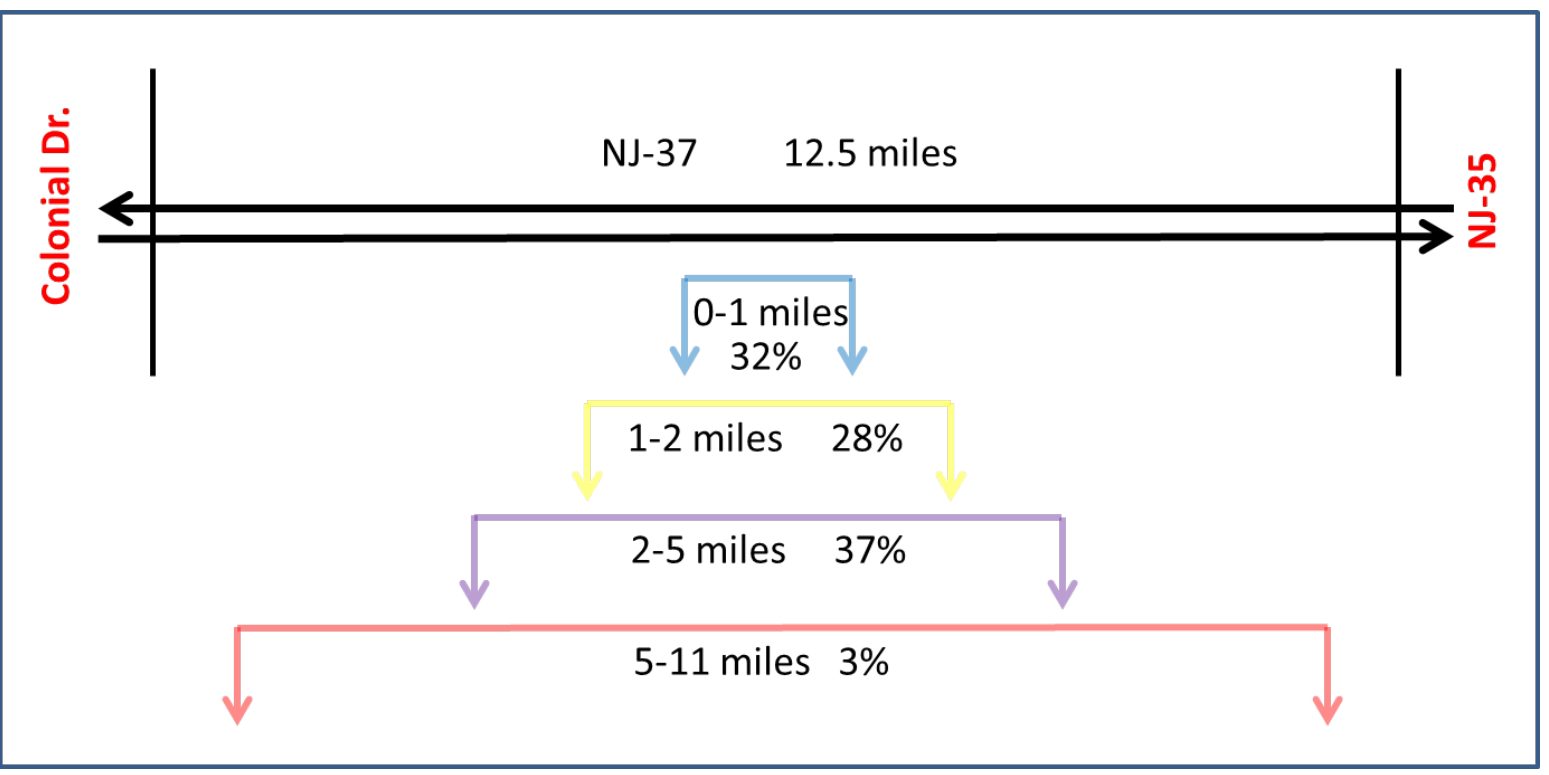

Figure 13 Use of corridor graphic 


\section{$4 \quad$ Results and Conclusions}

Methods to classify where a roadway falls on the mobility versus land access spectrum have traditionally relied on professional judgment based on geometric attributes. The Roadway Trip Length Characteristic (RTLC) provides a method to directly assess how the roadway is used by drivers. With modern reidentification equipment, the base data can be collected cost effectively. The distribution of trip length can provide insight on roadway function at various times of day, which in turn can be compared with regulatory and/or signal timing to insure they are in harmony.

The trip length statistic is an objective measure directly reflecting the subjective concept of throughput versus land access. As a directly measurable attribute, it is useful for engineering and performance assessment processes. It can supplant subjective judgment or indirect measures to provide a repeatable and defendable method for classifying roadways in order to compare and contrast roadway operations. Moreover, it can also be used to find like roadways across broad geographical spaces to compare for performance as illustrated in Figure 14 below which contracts RTLC between MD140 and NJ37 from the two case studies.

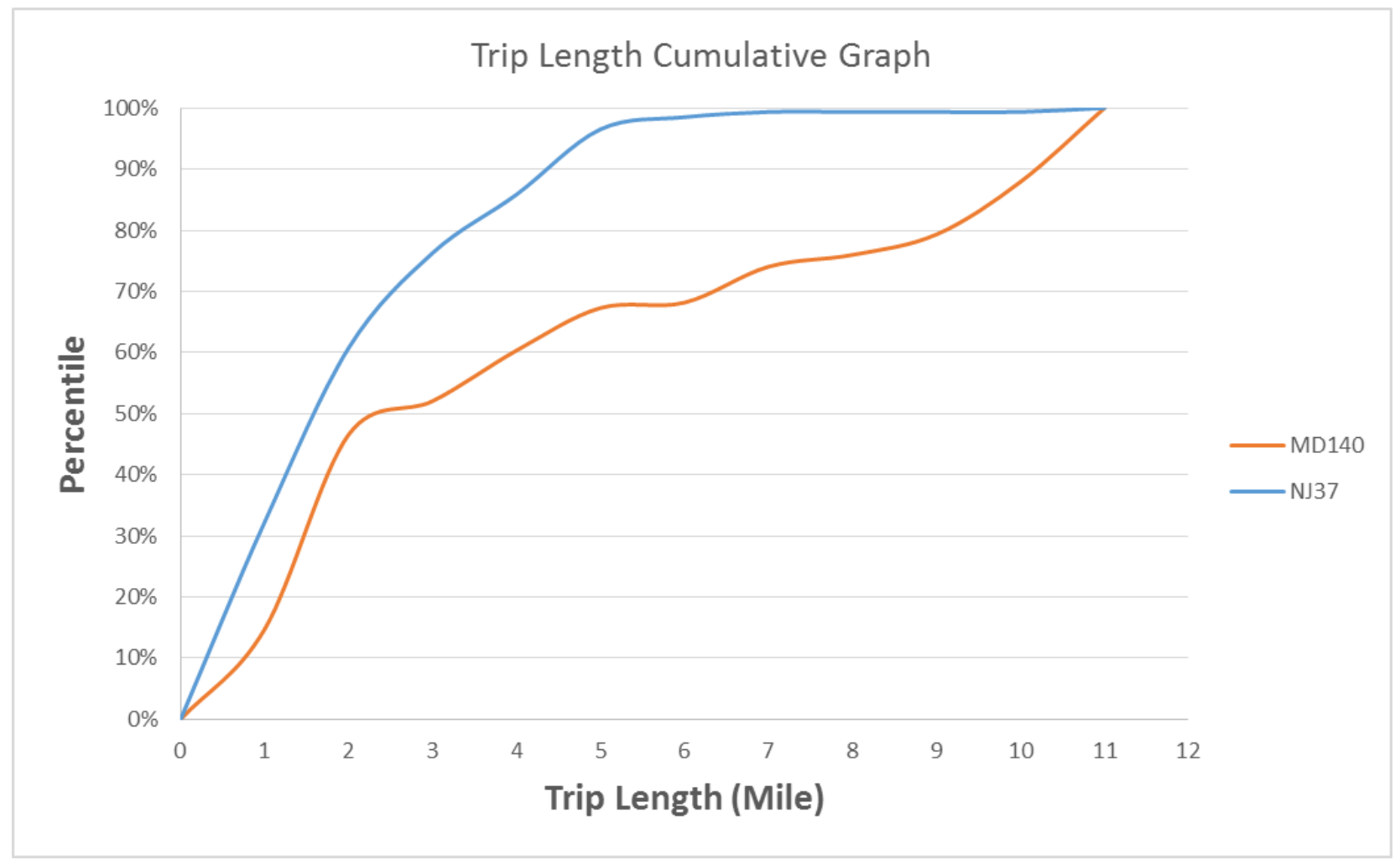

Figure 14 Cumulative frequency diagram of trip lengths in Case Study I \& Case Study II

Whereas the through movements to access Interstate 795 was a dominant use of Maryland Route 140 in Case Study I, the trip lengths in Case Study II were more evenly distributed across multiple trip lengths. Although a large number of vehicles access the major highway (Garden State Parkway) at the mid-point of New Jersey Route 37, it was not as dominant on NJ Route 37 as it was on MD-140. 
Data and inferences gained from the RTLC method allow for comparisons of vehicle traffic operations either on the same facility (different times of day) or between two different facilities. This provides a valuable tool for management policy, signal timing and coordination schemes, and other operations treatments.

Although Case Study I and II were illustrated with Bluetooth based re-identification data, the RTLC is not restricted to any particular type of re-identification data, nor is it only applicable to re-identification data. As modern data sources continue to mature, individual vehicle location data can also be used as the basis for calculating RTLC information. Data sources such as vehicle probe based traffic data and vehicle-tovehicle dedicated short-range communication are anticipated to provide such data in the future.

The RTLC method provides a repeatable and objective procedure to characterize roadway function based on how it is used by drivers. The RTLC also complements classification by design attributes and allows for a higher granularity approach to roadway characterization. 


\section{Glossary}

\section{Gap-out}

A time threshold setting in Bluetooth re-identification technology which determines the time that must transpire between successive observations of the same MAC ID before a new detection record is created. It is typically set between 5 and 30 minutes.

\section{Geometric Attributes of Arterials}

Various physical characteristics of arterial roadways which impact the tradeoff between throughput and land access, The attributes of most interest include:

- $\quad$ Lanes - the minimum and maximum number of through lanes.

- Number of Access Points - non-signalized intersections with other roads and entrances to business and high density residential properties.

- Median Barrier - the existence of a median barrier on the segment that prevents left hand turning movements except at designated access areas.

- Number of Major Junctions - the number of junctions with another roadway of significantly higher class such that the segment acts as a feeder/distributer to another roadway at that junction.

\section{Operational Attributes of Arterials}

Various use and management characteristics of arterial roadways which impact the tradeoff between throughput and land access, The attributes of most interest include:

- $\quad$ Signals -

o Number: the total number of signalized intersections within the area of study

o Density: calculated by number of signals divided by segment length

- $\quad$ AADT - the minimum and maximum Annual Average Daily Traffic

- $\quad$ Speed Limit - posted speed limit.

\section{Person Vehicle Trip}

The path that a vehicle takes from the origin to the destination to accomplish a goal or purpose, such as going to work.

\section{Roadway Trip Length Characteristic (RTLC)}

A method of measuring roadway trip lengths and the statistical distribution of those trip lengths on a specific facility to objectively characterize roadway function on the scale of throughput versus landaccess. The statistical distribution of roadway trip lengths on a specific facility provides information about how the facility is utilized by the traveling public. The distribution of trip lengths can in turn be compared to the roadway design and prevailing signal timing plans to see if they are in harmony. Roadways with predominantly short trip lengths are anticipated to favor land access over throughput, and conversely those with predominantly long trip lengths are anticipated to favor throughput over land access. The amount and extent of variation of trip length on a facility provides an indication of the conflicting demand on the roadway. 


\section{Roadway Vehicle Trip}

The portion of a person vehicle trip that occurs on the roadway under study. A roadway vehicle trip begins once the vehicle enters the roadway and ends when it departs.

\section{Trip Chain}

The record of travel between two established points. The trip may be direct between these two points or may include one or more stops. Within the context of this work, a trip chain is described as the path taken along a roadway between two sensors. If intermediate sensors are passed, they are included in the trip chain. For example, a trip that originated at sensor $C$ on the roadway corridor, exited at sensor F, and traveled by sensors D and E would be designated as a CDEF trip chain. 


\section{Bibliography}

[1] N. Spiller, "Federal Highway Administration, Office of Operations, Access Management Principles Presentation," [Online]. Available:

http://www.ops.fhwa.dot.gov/access_mgmt/presentations/am_principles_intro/index.htm. [Accessed 5 July 2016].

[2] A. Brooks, "State of Alaska Fairview Loop Rehabilitation FAQs," Brooks \& Associates, [Online]. Available: http://www.brooks-alaska.com/fairviewloop/faqs.htm. [Accessed 5 July 2016].

[3] M. Spack, "The Dos and Don'ts of Access Management," Mike On Traffic - Musings of a Professional Engineer, [Online]. Available: http://www.mikeontraffic.com/dos-donts-access-management/. [Accessed 5 July 2016].

[4] S. Young, M. Hamedi, E. Sharifi, R. Morris-Juster, K. Kaushik and S. Eshragh, "I-95 Corridor Coalition Vehicle Probe Project Validation of Arterial Probe Data," July 2015. [Online]. Available: http://i95coalition.org/wp-content/uploads/2015/02/I-95_Arterial_Validation_Report_July2015FINAL.pdf?dd650d. 


\section{Report Sponsor}

The "Small Business Innovation Development Act of 1982" (Pub. L. No. 97-219), along with reauthorizing legislation (Pub. L. No. 99-443 and Pub. L. No. 102-564, the "Small Business Research and Development Enhancement Act of 1992"), seeks to encourage the initiative of the private sector and to use small business effectively to meet federal research and development objectives. To comply with statutory obligations of the Act, the U.S. Department of Transportation established the Small Business Innovation Research (SBIR) Program, which conforms to the guidelines and regulations provided by the Small Business Administration. Annually, small businesses are solicited to submit innovative research proposals that address the high-priority requirements of the U.S. Department of Transportation and that have potential for commercialization.

This report was developed through a partnership between Traffax, Inc., and Purdue University with funding from a Phase III SBIR contract (DTFH6114C00035) with the Federal Highway Administration. The project, entitled "Sensor Fusion and MOE Development for Off-Line Traffic Analysis of Real Time Data," created and refined methods and tools for the characterization of performance along arterial corridors.

\section{Publication}

This report is part of a series of reports published in collaboration with USDOT, Traffax, Inc., and Purdue University. The full report series is available for download at http://docs.lib.purdue .edu/apmtp/.

\section{Open Access and Collaboration with Purdue University}

The Indiana legislature established the Joint Highway Research Project in 1937. In 1997, this collaborative venture between the Indiana Department of Transportation and Purdue University was renamed as the Joint Transportation Research Program (JTRP) to reflect state and national efforts to integrate the management and operation of various transportation modes. Since 1937, the JTRP program has published over 1,600 technical reports. In 2010, the JTRP partnered with the Purdue University Libraries to incorporate these technical reports in the University's open access digital repository and to develop production processes for rapidly disseminating new research reports via this repository. Affiliated publications have also recently been added to the collection. As of 2017, the JTRP collection had over 1.5 million downloads, with some particularly popular reports having over 20,000 downloads. 